\title{
Reply to "Basal buoyancy and fast-moving glaciers: in defense of analytic force balance" by C. J. van der Veen (2016)
}

\author{
Terence J. Hughes ${ }^{1}$ * \\ ${ }^{1}$ Climate Change Institute and School of Earth and Climate Sciences University of Maine, 404 North Sixth Street, \\ Fort Pierre, South Dakota 57532, USA \\ * retired
}

Correspondence to: Terence J. Hughes (terry.hughes@ maine.edu)

Received: 12 January 2017 - Discussion started: 31 January 2017

Revised: 20 June 2017 - Accepted: 27 June 2017 - Published: 21 July 2017

\begin{abstract}
Two approaches to ice-sheet modeling are available. Analytical modeling is the traditional approach (Van der Veen, 2016). It solves the force (momentum), mass, and energy balances to obtain three-dimensional solutions over time, beginning with the Navier-Stokes equations for the force balance. Geometrical modeling employs simple geometry to solve the force and mass balance in one dimension along ice flow (Hughes, 2012a). It is useful primarily to provide the first-order physical basis of ice-sheet modeling for students with little background in mathematics. The geometric approach uses changes in ice-bed coupling along flow to calculate changes in ice elevation and thickness, using a floating fraction $\phi$ along a flow line or flow band, where $\phi=0$ for sheet flow, $0<\phi<1$ for stream flow, and $\phi=1$ for shelf flow. An attempt is made to reconcile the two approaches.
\end{abstract}

\section{Introduction}

Cornelis "Kees" Van der Veen's comparison of geometric and analytic approaches to the force balance in glaciology in The Cryosphere (Van der Veen, 2016) is most welcome because he takes seriously my geometrical approach to the longitudinal force balance (Hughes et al., 2016). The geometric force balance is useful only for one-dimensional flow along ice-sheet flow lines or flow bands of constant width. For twodimensional flow in the map plane, width becomes a variable and geometrical areas become geometrical volumes, substantially increasing geometrical complexity with little advance in physical insight. The analytic force balance is typically obtained by solving the Navier-Stokes equations, which can be done in three dimensions and, when including the mass and energy balances, becomes time dependent. The geometrical approach has the advantage of being visual. It is useful for visually understanding the force balance by comparing the areas of right triangles and rectangles (or parallelograms).

\section{Addressing Van der Veen (2016)}

My interest in the force balance for ice sheets spans four decades, beginning when I used glacial geology to reconstruct former ice sheets from the bottom up based on the strength of ice-bed coupling deduced from glacial geology, an approach that also produced the concave surface of ice streams for the first time (Denton and Hughes, 1981, chap. 5 and 6). I developed the geometric approach after observing the huge arcing transverse crevasses at the head of Byrd Glacier, and realized it was actually pulling ice out of the East Antarctic Ice Sheet (Hughes, 1992). Since then it has been a work in progress.

Referring to Hughes (2008), Van der Veen (2016) states on his page 1332 that I believe lateral drag vanishes at the center of an ice stream. Lateral shear stress $\sigma_{x y}$ vanishes, but the lateral shear force does not. On the right side, stress $\sigma_{x y}$ acts on side area $\boldsymbol{A}_{y}$ and on the left side stress $-\sigma_{x y}$ acts on side area $-\boldsymbol{A}_{y}$, with $\boldsymbol{A}_{y}$ and $-\boldsymbol{A}_{y}$ being vectors in opposite $y$ directions, so the shear force is always positive and opposes longitudinal gravitational forcing. 
Van der Veen (2016) states that his Eq. (9) is similar to my Eq. (36) in Hughes (2003), but it is not the same. We cannot readily translate term by term the geometric balance in the conventional notation of the force balance. It is just the same equation that holds.

In the geometric force balance, the driving force is the area of a right triangle and all the resisting forces are areas of triangles and a rectangle (or parallelogram) that fit into the triangle so the driving and resisting forces are identical. All signs are positive in my Eq. (36). His $\sigma_{\mathrm{F}}$ is my flotation stress, which does not appear in my 2003 paper. It appears in Hughes (2012a) and in Hughes et al. (2016). Van der Veen $\left(2016\right.$, p. 1333) states my $\sigma_{\mathrm{F}}$ is his $\widetilde{R}_{x x}$ in his Eq. (1). It is not. My $\sigma_{\mathrm{F}}$ always requires basal water deep enough to uncouple ice from the bed or to supersaturate basal till; see my Fig. 1. In ice streams, water height $h_{\mathrm{W}}$ above the bed is the height to which basal water would rise in a borehole, including heights far above sea level (Kamb, 2001). There is no such provision in Van der Veen (2016).

The proof that my $\sigma_{\mathrm{F}}$ is unique is found using my equations, reproduced in my Table 1 from Table 12.1 in Hughes (2012a). Substituting my equations for $\partial\left(\sigma_{\mathrm{F}} h_{\mathrm{I}}\right) / \partial x$, $\tau_{\mathrm{O}}$, and $\tau_{\mathrm{S}}$ expressed in terms of floating fraction $\phi$ into $P_{\mathrm{I}} \alpha=\partial\left(\sigma_{\mathrm{F}} h_{\mathrm{I}}\right) / \partial x+\tau_{\mathrm{O}}+2 \tau_{\mathrm{S}}\left(h_{\mathrm{I}} / w_{\mathrm{I}}\right)$, my equation for the force balance, gives $0=0$. In my geometric force balance, resisting forces are represented by triangles and a rectangle (or parallelogram) that exactly fit inside a big right triangle that represents my driving force, so the area of my big triangle is the same as summed component areas from resisting forces within it, so $0=0$ must be obtained; see the visual representation in my Fig. 2.

Referring to my Fig. 3 (left), Fig. 3 in Van der Veen (2016), line AF should be parallel to line BE because they both show ice pressure increasing linearly with depth. Line CE shows how water pressure increases linearly with depth, as is obvious at the calving front. In my geometrical force balance, the longitudinal gravitational driving force is area ADF of the big right triangle. Fitted inside ADF are a resisting flotation force given by area BDE for floating ice fraction $\phi$ and a resisting drag force given by area ABEF for the grounded ice fraction $1-\phi$ in my Fig. 1. Inside BDE is area CDE for the resisting force from water pressure and area $\mathrm{BCE}$ for the resisting force from the tensile strength of floating ice. Inside area ABEF is the triangle above B for basal drag and the parallelogram below B for side drag. Resistance from basal drag is the area of the triangle above B. Resistance from side drag is the area of the parallelogram below $\mathrm{B}$ if lines $\mathrm{BE}$ and $\mathrm{AF}$ are made parallel. If $\mathrm{BE}$ is made part of $\mathrm{AF}$, a rectangle would replace the parallelogram but the area would be unchanged; see my Fig. 2. That is all there is to it. The only remaining task is to replace forces with products of stresses and lengths (for areas with zero or constant widths along $x$ ) upon which the stresses act along a flow line (no width) or a flow band (constant width). My solution for the force balance is exact because forcing area $\mathrm{ADF}$ equals resisting areas $\mathrm{ABEF}, \mathrm{BCE}$,

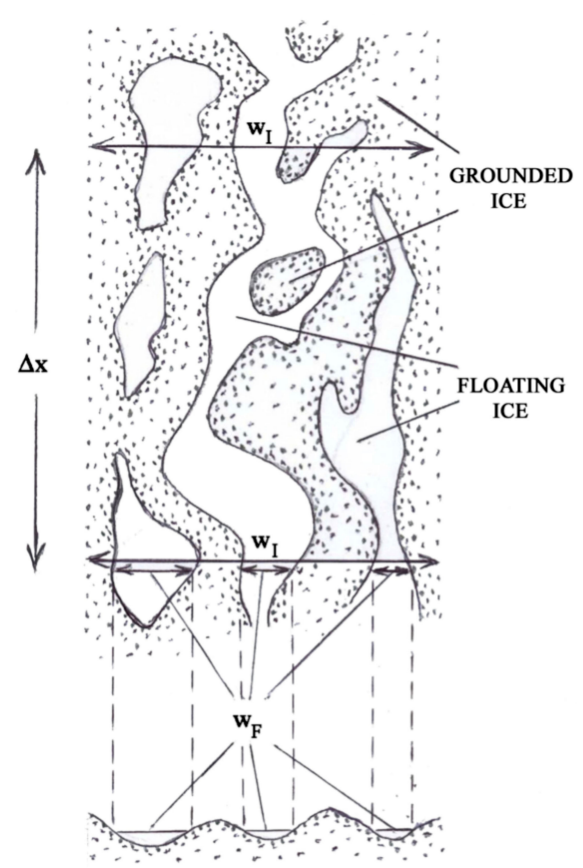

Figure 1. Figure 4 from Hughes et al. (2016). Under an ice stream, basal ice is grounded in the shaded areas and floating in the unshaded areas (top) as seen in a transverse cross section (bottom) for incremental basal area $w_{\mathrm{I}} \Delta x$.

and $\mathrm{CDE}$ inside ADF. All gravitational and resisting forces in the longitudinal direction of ice flow are thereby included, with ABEF representing the force from both basal and side drag.

Van der Veen (2016) correctly states that his Eq. (16) represents my longitudinal gravitational driving force, but then he states it "does not represent the gravitational driving force" (p. 1335). It does. The analytic and geometric approaches to the force balance must be presented and understood each on their own terms. Attempts to mix the two, as Van der Veen (2016) did, leads only to confusion.

Van der Veen (2016) states on his page 1335 that a longitudinal force balance along $x$ must be made over incremental distance $\Delta x$ that shrinks to zero. My longitudinal force balance along $x$ does; see Hughes (2012a, Appendix G) and Hughes et al. (2016, p. 10). I subtract longitudinal force areas over distance $\Delta x$ to get my longitudinal force balance Eq. (22) in Hughes et al. (2016). However, Van der Veen (2016) is incorrect in stating a longitudinal force balance must always be made over length $\Delta x$. At the calving front of an ice shelf the balance is obtained right at the calving front where $\Delta x=0$, as Robin (1958) proved 59 years ago geometrically.

Van der Veen (2016) states that his Fig. 4a, reproduced in my Fig. 3 (right panels), should represent my geometrical force balance because his area ADF equals his area APD. It would if he divided his area APD into my smaller areas of triangles and a rectangle shown in my Fig. 2, areas that resist 

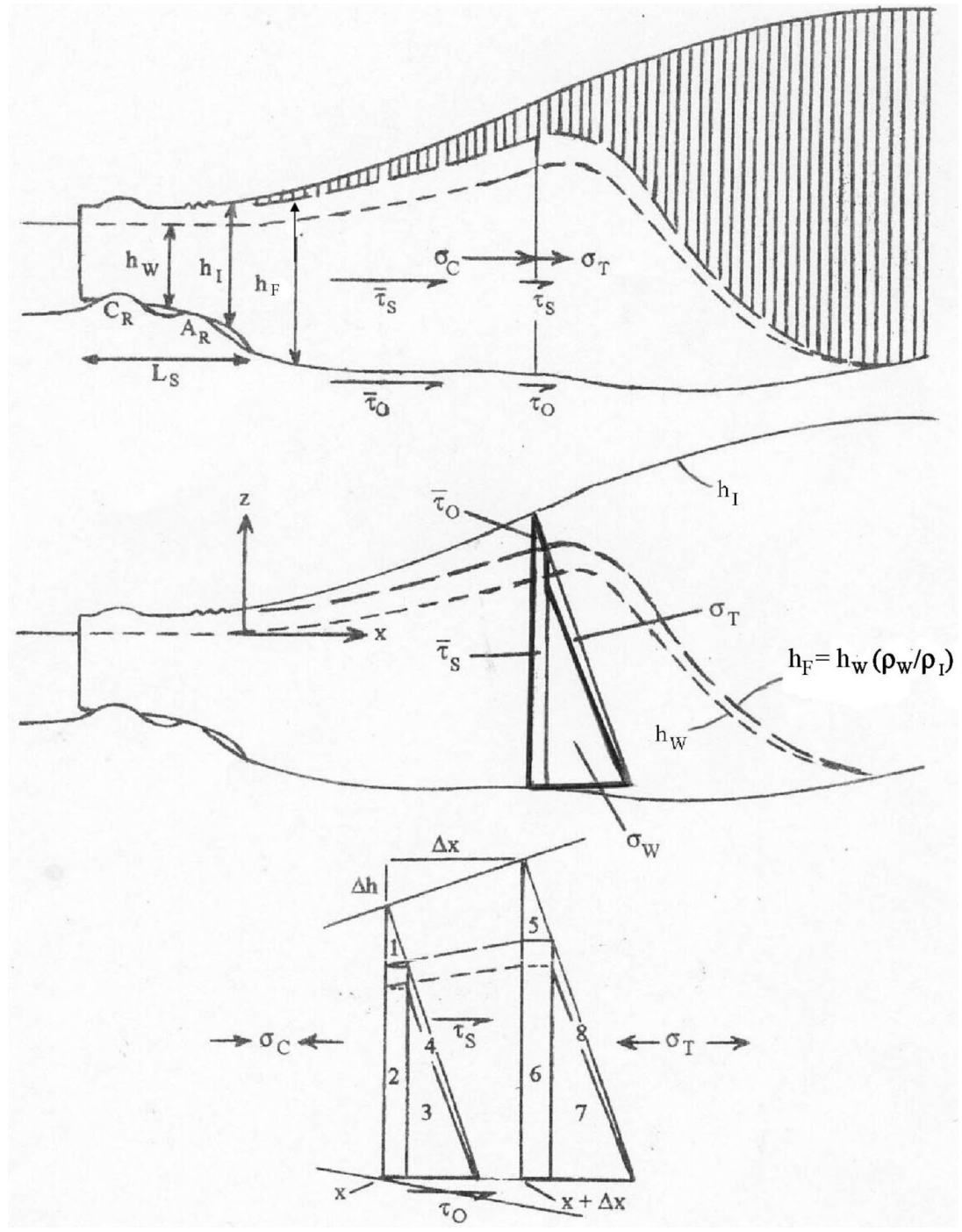

Figure 2. Figure 5 from Hughes et al. (2016). Top: stresses at $x$ and downstream from $x$ that resist gravitational forcing. The bed supports ice in the shaded area. Middle: the gravitational force inside the thick border is linked to $\sigma_{\mathrm{C}}$, which represents all downstream resistance to ice flow at point $x$. Bottom: gravitational forces (geometrical areas 1 through 8 ) and resisting stresses along incremental downstream length $\Delta x$ at point $x$.
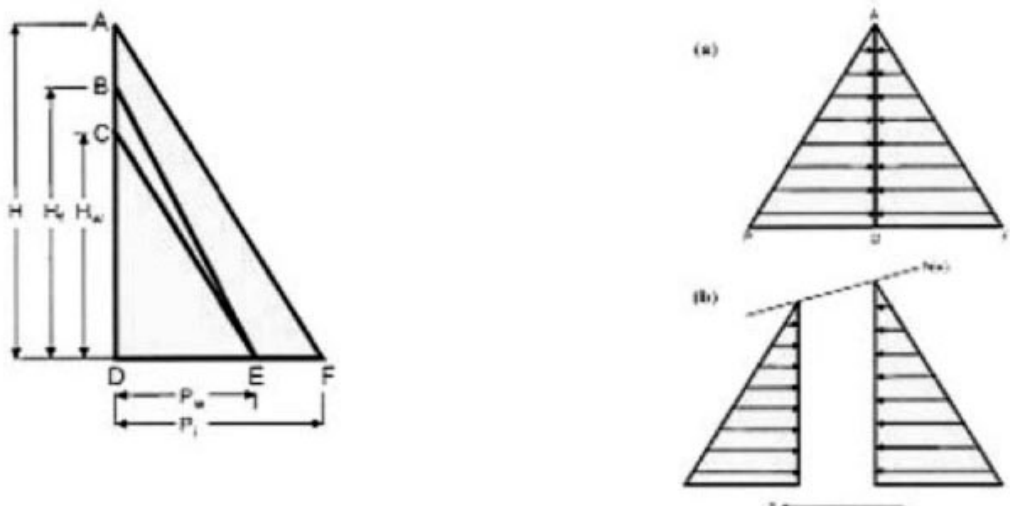

Figure 3. Figure 3 (left) and Fig. 4 (right) from Van der Veen (2016). 
Table 1. Resisting stresses linked to floating fraction $\varphi=P_{\mathrm{F}} / P_{\mathrm{I}}$ of ice and gravitational forces numbered in Fig. 2 for the geometrical force balance.

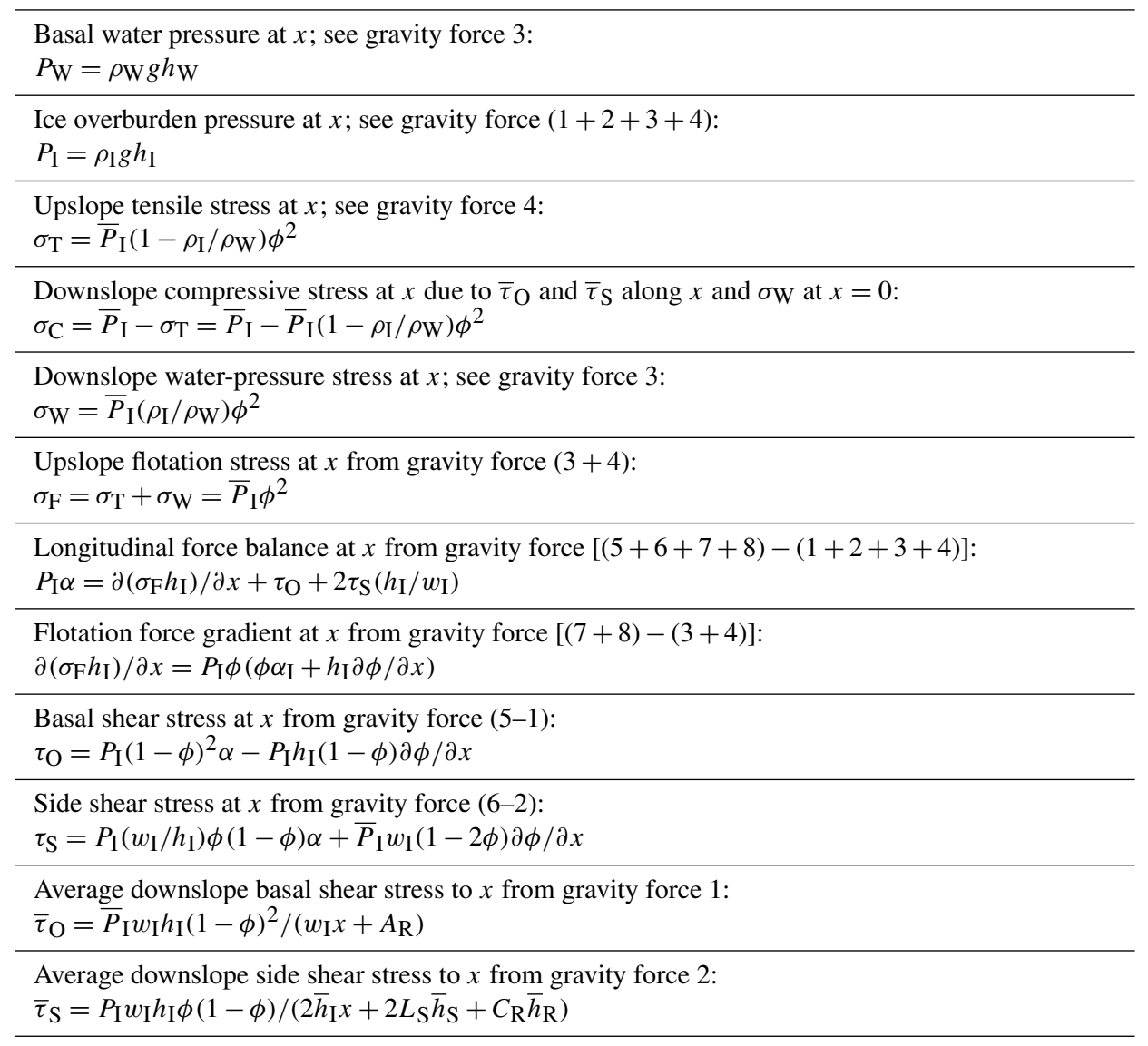

gravitational forcing from his area ADF. He states that both areas ADF and APD are "lithostatic stresses". They are not. Area ADF is my gravitational driving force and area APD is the sum of my resisting forces opposing the driving force, as he shows by his horizontal arrows in his Fig. 4a. There is no surface slope in his Fig. 4a. That condition applies to an unconfined linear ice shelf with constant thickness (Weertman, 1957; Robin, 1958), in which case only my areas 3 and 4 in my Fig. 2 (bottom) add to give his area APD, since there are no basal and side drag forces represented by my areas 1 and 2. Raymond (1983) analyzed deformation near interior ice divides where the surface slope is also zero.

In his Fig. 4b, shown in my Fig. 3b, Van der Veen (2016) correctly shows the geometrical force balance in my Fig. 2 (bottom) for a sloping ice surface above a horizontal bed. From these figures we can both obtain the geometric longitudinal force balance over incremental length $\Delta x$ in analytic form when $\Delta x \rightarrow 0$. In my Fig. 2 (bottom), my big right triangles at $x$ and $x+\Delta x$ are gravitational driving forces that are respectively subdivided into areas 1, 2, 3, 4 and areas 5, $6,7,8$, which resist gravitational motion along $x$.

Resistance from my $\sigma_{\mathrm{W}}$ may be akin to bridging stresses across water-filled cavities discussed by Van der
Veen (2016). The existence of $\sigma_{W}$ in the geometric force balance is not readily apparent from analytic solutions of the Navier-Stokes equations, but Van der Veen (2016) may have teased it out with his bridging stress, which forces him to add resistance by including steep shear-stress gradients on each side of his cavities. He maintains his cavities are small so these gradients average out to zero along an ice stream, eliminating the need for my $\sigma_{\mathrm{W}}$. They cannot average to zero if his cavities are water-filled and get bigger and closer together downstream, as required to progressively uncouple ice from the bed. Then cavities themselves have a size and distribution gradient. Figure 1, which is Fig. 4 in Hughes et al. (2016), shows my concept of water-filled cavities in area $w_{\mathrm{I}} \Delta x$ under an ice stream. We do not know which concept of cavities is correct.

\section{Concluding remarks}

My geometrical force balance aims to teach the fundamentals of glaciology to students with an inadequate background in mathematics, usually students studying to be glacial geologists (Hughes, 2012a). My geometrical approach was de- 
signed to make maximum use of glacial geology in reconstructing former ice sheets from the bottom up (Hughes, 1998, chap. 9 and 10; Fastook and Hughes, 2013) and in demonstrating how basal thermal conditions produce glacial geology under the Antarctic Ice Sheet today (Hughes, 1998, chap. 3, Wilch and Hughes, 2000; Siegert, 2001). Previously I had spent more time teaching calculus than glaciology because the Navier-Stokes equations had to be integrated in the force balance. Everyone knows the area of a rectangle is base times height, and of a triangle is half that; yet knowing that delivers the same results as integrating the NavierStokes equations for linear sheet, stream, and shelf flow.

I developed the geometrical force balance over some decades, from Hughes (1992) through to Hughes et al. (2016). My papers are a work in progress; see pages 201202 of Hughes et al. (2016) regarding $h_{\mathrm{W}}, h_{\mathrm{F}}, \sigma_{\mathrm{W}}$, and $\sigma_{\mathrm{F}}$ not included in earlier papers. To access my most recent thinking, see Hughes (2012a) and Hughes et al. (2016). All the earlier studies are flawed in various ways. The last ones may also have flaws I have not detected. Some criticisms by Van der Veen (2016) are directed at my earlier flawed papers.

This response gives me an opportunity to correct three mistakes in Hughes (2012a) that will be apparent to careful readers. The first line in Eq. (12.9) should be

$\partial\left(\sigma_{\mathrm{F}} h_{\mathrm{I}}\right) / \partial x=\partial\left[\frac{1}{2} \rho_{\mathrm{I}} g h_{\mathrm{I}}^{2} \phi^{2}\right] / \partial x=P_{\mathrm{I}} \phi\left(\phi \alpha_{\mathrm{I}}+h_{\mathrm{I}} \partial \phi / \partial x\right)$.

In the denominator of Eq. (17.18), $r$ should be replaced by $(a-r)$. The first line of Eq. (22.18) should be

$$
\begin{aligned}
\Delta h_{i}^{*} / \Delta x & =\phi^{2}\left(\frac{\Delta h_{\mathrm{I}}}{\Delta_{x}}\right)_{i}+\left(\frac{h_{\mathrm{I}}}{2}\right)_{i} \frac{\Delta \phi^{2}}{\Delta x}+\frac{\left(\tau_{\mathrm{O}}\right)_{i}}{\rho_{\mathrm{I}} g h_{\mathrm{I}}^{*}}+\frac{2\left(\tau_{\mathrm{S}}\right)_{i}}{\rho_{\mathrm{I}} g w_{\mathrm{I}}} \\
& =\frac{\left(\tau_{\mathrm{O}}^{*}\right)_{i}}{\rho_{\mathrm{I}} g h_{\mathrm{I}}^{*}} .
\end{aligned}
$$

Equation (22.18) applies to sheet flow when $\phi=\partial \phi / \partial x=0$ and $\tau_{\mathrm{O}}^{*}$ increases resistance from basal drag $\tau_{\mathrm{O}}$ by including side drag $\tau_{\mathrm{S}}$ in flow bands with some side shear to allow for the possibility of thermal convection in the form of rolls under ice-stream tributaries (Hughes, 2012b). If $\phi>0$ in tributaries supplying ice streams, and since tributaries are ubiquitous in the sheet-flow interior of the Antarctic Ice Sheet (Hughes, 2012b), side shear must be taken into account even for sheet flow because tributaries are flow bands that move faster than ice between these flow bands.

Data availability. No data sets were used in this article.

Competing interests. The author declares that he has no conflict of interest.

Acknowledgements. I thank Cornelis van der Veen for giving me the opportunity to further explain my geometric force balance in relation to the standard analytic force balance. I thank the editor, Frank Pattyn, for allowing my explanation to appear in The Cryosphere. I especially thank the reviewers, including Cornelis Van der Veen and Frank Pattyn, who contributed to the interactive discussion. Wording by Frank Pattyn to highlight difficulties in trying to combine the geometric and analytic force balances using equations that are similar but not identical has been incorporated. As always, reviewers are worth their weight in gold.

Edited by: Frank Pattyn

Reviewed by: Cornelis Van der Veen and one anonymous referee

\section{References}

Denton, G. H. and Hughes, T. J. (Eds.): The Last Great Ice Sheets, Wiley Interscience, New York, 484 pp., 1981.

Fastook, J. L. and Hughes, T. J.: New perspectives on paleoglaciology, Quaternary Sci. Rev., 80, 169-194, 2013.

Hughes, T.: On the pulling power of ice streams, J. Glaciol., 38, 125-151, 1992.

Hughes, T. J.: Holistic ice sheet modeling: a first-order approach (monograph), University of Maine, 188 pp., 2008.

Hughes, T.: Holistic Ice Sheet Modeling: A First-Order Approach, Nova Publishers, New York, 261 pp., 2012a.

Hughes, T.: Are ice-stream tributaries the surface expression of thermal convection rolls in the Antarctic ice sheet?, J. Glaciol., 58, 811-814, 2012b.

Hughes, T., Sargent, A., Fastook, J., Purdon, K., Li, J., Yan, J.-B., and Gogineni, S.: Sheet, stream, and shelf flow as progressive ice-bed uncoupling: Byrd Glacier, Antarctica and Jakobshavn Isbrae, Greenland, The Cryosphere, 10, 193-225, https://doi.org/10.5194/tc-10-193-2016, 2016.

Hughes, T. J.: Ice Sheets, Oxford Univ. Press, Oxford, UK, 343 pp., 1998.

Hughes, T. J.: Geometrical force balance in glaciology, J. Geophys. Res., 107, 2526, https://doi.org/10.1029/2003JB002557, 2003.

Kamb, B.: Basal zone of the West Antarctic ice streams and its role in lubrication of their rapid motion, in: The West Antarctic Ice Sheet: Behavior and Environment, edited by: Alley, R. B. and Bindschadler, R. A., Antarctic Research Series, American Geophysical Union, Washington, D.C., 157-200, 2001.

Raymond, C. F.: Deformation in the vicinity of ice divides, J. Glaciol., 29, 357-373, 1983.

Robin, G. de Q.: Glaciology III: Seismic shooting and related investigations. Scientific Results of the Norwegian, British, Swedish Antarctic Expedition, 1949-1952, 5, 111-125, 1958.

Siegert, M. J.: Comments on "Calculating basal thermal zones beneath the Antarctic Ice Sheet" by Wilch and Hughes (letter), J. Glaciol., 47, 159-160, 2001.

van der Veen, C. J.: Basal buoyancy and fast-moving glaciers: in defense of analytic force balance, The Cryosphere, 10, 13311337, https://doi.org/10.5194/tc-10-1331-2016, 2016.

Weertman, J.: Deformation of floating ice shelves, J. Glaciol., 3, 38-42, 1957.

Wilch, E. and Hughes, T.: Mapping basal thermal zones beneath the Antarctic ice sheet, J. Glaciol., 46, 297-310, 2000. 